\title{
Analisis Variabilitas dan Heritabilitas Mutan Padi (Oryza Sativa L.) M3 Hasil Iradiasi Sinar Gamma Pada Sistem Pertanian Organik
} (Analysis of Variability and Heritability of Rice Mutants (Oryza Sativa L.) M3 Results of Gamma Ray Irradiation in Organic Farming Systems)

\author{
Irsat Adanan Harahap ${ }^{1}$, Efendi ${ }^{1}$, Syafruddin ${ }^{1}$ \\ ${ }^{1}$ Program Studi Agroteknologi, Fakultas Pertanian, Universitas Syiah Kuala
}

\begin{abstract}
Abstrak: Iradiasi sinar gamma menyebabkan terjadinya perubahan genetika pada padi Sanbei Mutan yang diwariskan keketurunannya. Tujuan penelitian ini adalah untuk mengetahui heritabilitas padi mutan 3 terhadap induknya M2. Metode penilitian yang digunakan adalah Analisis Deskriptif yang ditata dalam bentuk rancangan acak lengkap $(R A L)$ non faktorial, menggunakan satu faktor pengaruh galur dengan Sanberasi M3 ada 37 galur dan Sanbei Asli 3 ulangan total 40 galur. Bahan yang digunakan adalah benih padi, kapas, air, pupuk organik, pupuk daun, dekomposer, tanah entisol, dan Alat yang digunakan adalah petridish, incubator, ayakan tanah, head magnifier, meteran, kamera, pinset, tray, ember besar, klip plastik kecil. Hasil penelitian menunjukkan bahwa beberapa galur M3 memiliki heritabiltas tinggi, cukup tinggi dan rendah terhadap induknya M2 pada pengamatan tinggi tanaman, jumlah anakan produktif, panjang malai, tinggi tanaman, berat malai dan jumlah malai. Perlakuan pengaruh galur membuat pertumbuhan padi Mutan 3 jadi beragam dan penanaman secara organik tak menjadi kendala produksi pada penanaman padi Mutan 3.
\end{abstract}

Kata Kunci: Padi Mutan, Heritabilitas, Iradiasi, Pertanian Organik

\begin{abstract}
Gamma ray irradiation causes genetic changes in Sanbei mutant rice inherited from their descendants. The purpose of this study was to determine the heritability of mutant 3 rice to its parent M2. The research method used was Descriptive Analysis which was arranged in a nonfactorial completely randomized design (RAL), using a factor of influence of strains with M3 Sanberation there were 37 lines and Original Sanbei 3 repetitions of a total of 40 lines. The materials used are rice, cotton, water, organic fertilizer, leaf fertilizer, decomposer, entisol soil, and the tools used are petridish, incubator, soil sieve, head magnifier, meter, camera, tweezers, tray, large bucket, plastic clips small. The results showed that several M3 strains had high heritability, were quite high and low on their parent M2 on observations of plant height, number of productive tillers, panicle length, plant height, panicle weight and number of panicles. The treatment of the effect of strains made the growth of Mutant 3 rice varied and organic planting did not become an obstacle to production in Mutant 3 rice cultivation.
\end{abstract}

Keywords: Mutant Rice, Heritability, Irradiation, Organic Farming

\section{PENDAHULUAN}

Iradiasi yang dilakukan pada tanaman pangan khususnya padi, lebih ditujukan untuk mengurangi karakter negatif dan meningkatkan karakter positif. Iradiasi diharapkan dapat menghasilkan mutan atau tanaman yang telah bermutasi dengan sifat yang dikehendaki, seperti memiliki anakan produktif yang banyak, mampu beradaptasi dengan lingkungan budidaya,dan memiliki masa berbunga yang cepat serta umur panen yang pendek (Alamsyah, 2016).

Galur Sanberasi M3 yang ditanam berasal dari Varietas Sanbei yang berasal dari Kab.Simeulue, Aceh. Varietas Sanbei kemudian dilakukan irradiasi gamma di Batan, kemudian hasil irradiasi ditanam sehingga menghasilkan 
Sanberasi M2 hasil dari galur Sanberasi M2, kemudian di seleksi pedigree sehingga didapat Sanberasi M2 yang paling unggul atau memiliki sifat yang di inginkan, kemudian Sanberasi M2 yang unggul di tanam lagi sehingga di dapatkan hasilnya Sanberasi M3 yang diharapkan sama dengan induknya Sanberasi M2 (Putra, 2016).

Seleksi Silsilah untuk mendapatkan varietas baru dengan mengkombinasikan gen-gen yang di inginkan yang ditemukan pada dua fenotipe atau lebih. Rekombinasi dari dua genotipe atau lebih tersebut diharapkan menghasilkan turunan yang lebih baik dan unggul dibandingkan rata-rata kedua tetuanya. Pemilihan tetua merupakan hal yang sangat penting. Tetua dipilih karena mempunyai sifat yang di inginkan, diatur oleh gen yang mempunyai potensi untuk digabungkan. Secara Umum, salah satu tetua dipilih karena : (1) sudah beradaptasi dan diterima oleh masyarakat; (2) sifat komplemen yang tidak di miliki oleh tetua lain, misalnya ketahanan terhadap penyakit (Syukur et al., 2012).

Heritabilitas adalah perbandingan antara besaran ragam genotipe dengan besaran total ragam fenotipe dari suatu karakter. Hubungan ini menggambarkan seberapa jauh fenotipe yang tampak merupakan refleksi dari genotife. Faktor genetik tidak akan memperlihatkan karakter yang dibawanya, kecuali dengan adanya faktor lingkungan yang diperlukan. Sebaliknya, bagaimanapun orang mengadakan manipulasi dan perbaikan-perbaiakan terhadap faktor-faktor lingkungan, tak akan menyebabkan perkembangan suatu karakter, kecuali kalau faktor genetik yang diperlukan terdapat pada individu-individu atau populasi tanaman yang bersangkutan (Syukur et al., 2012).

\section{METODOLOGI PENELITIAN}

\section{Tempat dan Waktu}

Penelitian ini akan dilaksanakan pada beberapa tempat seperti pada perkecambahan benih dilakukan di Laboratorium Ilmu dan Teknologi Benih, Fakultas Pertanian, Universitas Syiah Kuala. Penanaman benih yang telah berkecambah dilaksanakan di Sawah Percobaan Fakultas Pertanian, Universitas Syiah Kuala, Darussalam, Banda Aceh, Posisi geografis $5.56^{\circ}$ lintang utara $95.37^{\circ}$ bujur timur dengan ketinggian 9.11 mdpl (Google Earth, 2016), pada bulan Maret 2016 sampai Juni 2016.

\section{Alat dan Bahan}

Bahan yang digunakan benih padi 40 galur, kapas, air, pupuk organik, pupuk daun, dekomposer, tanah, jerami dan Alat yang digunakan petridish, incubator, ayakan tanah, head magnifer, meteran, kamera, pinset, tray, ember besar,klip plastik kecil.

\section{Metode Penelitian}

Metode yang digunakan pada penilitian ini adalah Analisis Deskriftif yang ditata dalam bentuk rancangan acak lengkap (RAL) nonfaktorial dengan tanpa

Analisis Variabilitas dan Heritibilitas Mutan Padi (Oryza Sativa L.) M3 Hasil Iradiasi Sinar Gamma Terhadap Sistem Pertanian Organik (Irsat Adanan Harahap, Efendi, Syafruddin)

Jurnal Ilmiah Mahasiswa Pertanian Unsyiah, Vol. 4, No. 1, Februari 2019: 139-148 
ulangan, menggunakan pengaruh galur untuk melihat Heritabilitas dengan Metode Kalton, Smith, dan Leffel.

Tabel 1. Karakteristik Sanberasi M2

\begin{tabular}{|c|c|c|c|c|c|c|c|c|}
\hline Keterangan & $\begin{array}{c}\text { Tinggi } \\
\text { Tanama } \\
\mathrm{n}\end{array}$ & $\begin{array}{c}\text { Jumlah } \\
\text { Anakan }\end{array}$ & $\begin{array}{c}\text { Umur } \\
\text { Berbunga }\end{array}$ & $\begin{array}{l}\text { Umur } \\
\text { Panen }\end{array}$ & $\begin{array}{c}\text { Jumlah } \\
\text { Malai }\end{array}$ & $\begin{array}{c}\text { Panjang } \\
\text { Malai }\end{array}$ & $\begin{array}{l}\text { Berat } \\
\text { Malai }\end{array}$ & $\begin{array}{l}\text { Potensi } \\
\text { Hasil }\end{array}$ \\
\hline Rata-Rata & 117 & 15,4 & 70,6 & 100,8 & 13,4 & 26,8 & 51,56 & 9,0 \\
\hline Karakter & Sedang & Sedang & Cepat & Cepat & Sedang & Panjang & Sedang & Banyak \\
\hline Ragam M2 & 9,5 & 5,8 & 5,8 & 5,7 & 1,3 & 0,4 & 9,8 & \\
\hline
\end{tabular}

Tabel 2. Galur Sanberasi M3 yang digunakan dalam penelitian.

\begin{tabular}{llllll}
\hline NO & SANBERASI & Mutan & NO & SANBERASI & Mutan \\
\hline 1 & Sanbei 1 & M0 & 21 & S-36.b & M3 \\
2 & Sanbei 2 & M0 & 22 & S-67 & M3 \\
3 & Sanbei 3 & M0 & 23 & S-22.b & M3 \\
4 & S-V-1 & M3 & 24 & S-8 & M3 \\
5 & S-50.a & M3 & 25 & S-32 & M3 \\
6 & S-1 & M3 & 26 & S-55 & M3 \\
7 & S-53.a & M3 & 27 & S-13 & M3 \\
8 & S-50 & M3 & 28 & S-31 & M3 \\
9 & S-10 & M3 & 29 & S-46 & M3 \\
10 & S-6.b & M3 & 30 & S-33.a & M3 \\
11 & S-45 & M3 & 31 & S-72 & M3 \\
12 & S-53.b & M3 & 32 & S-44 & M3 \\
13 & S-76 & M3 & 33 & S-47 & M3 \\
14 & S-79 & M3 & 34 & S-48 & M3 \\
15 & S-80 & M3 & 35 & S-61 & M3 \\
16 & S-52 & M3 & 36 & S-33 & M3 \\
17 & S-15 & M3 & 37 & S-51 & M3 \\
18 & S-66 & M3 & 38 & S-70 & M3 \\
19 & S-5 & S-21 & 39 & S-41 & M3 \\
\hline
\end{tabular}

\section{a. Rancangan Percobaan}

Rancangan yang digunakan adalah rancangan acak lengkap(RAL) nonfaktorial. Total perlakuan adalah 37 galur M3 plot percobaan, dan 3 galur Sanbei Asli, sehingga seluruhnya berjumlah 40 plot percobaan.

\section{b. Parameter Pengamatan}

Variabel yang diamati terdiri dari tinggi tanaman saat panen, jumlah anakan produktif, Jumlah Malai, Panjang Malai, dan Berat Malai Per Rumpun.

\section{c. Pelaksanaan Penelitian}

Pelaksanaan penelitian terdiri dari:

Analisis Variabilitas dan Heritibilitas Mutan Padi (Oryza Sativa L.) M3 Hasil Iradiasi Sinar Gamma Terhadap Sistem Pertanian Organik (Irsat Adanan Harahap, Efendi, Syafruddin)

Jurnal Ilmiah Mahasiswa Pertanian Unsyiah, Vol. 4, No. 1, Februari 2019: 139-148 
1. Perkecambahan Benih

2. Penyiapan Media Persemaian

3. Penyiapan Lahan Penanaman

4. Penanaman di Lahan

5. Pemeliharaan : a. Penyulaman

b. Penyiraman

c. Pemberantasan Hama dan Gulma

6. Pengamatan Sampel

d. Pemberian Pupuk

7. Panen

\section{d. Analisa Data}

Data hasil penelitian dianalisis menggunakan ANOVA. Apabila hasil uji F menunjukkan berpengaruh nyata pada taraf $\alpha 5 \%$, maka analisis dilanjutkan untuk mengetahui beda rata-rata nilai tengah perlakuan dengan prosedur Uji Beda Nyata Terkecil (BNT) pada taraf uji $\alpha 5 \%$.

Adanya penghitungan Heritabilitas antara M3 dengan M2. Perhitungan heritabilitas memakai rumus:

1. Nilai Tengah $(\mathrm{x})$

$\mathrm{x}=\left(\sum \mathrm{x}\right) / \mathrm{n}$; dimana $\mathrm{n}$ merupakan banyaknya anggota populasi.

2. Ragam $\left(\sigma^{2}\right)$

$$
\sigma^{2}=\frac{\left(\sum \mathrm{x}^{2}\right)-\left[\left(\sum \mathrm{x}\right)^{2} / \mathrm{n}\right)}{\mathrm{n}-1}
$$

3. Metode Kalton, Smith, dan Leffel

Metode Kalton, Smith, dan Leffel (Kalton, Smith dan Leffel, 1952).

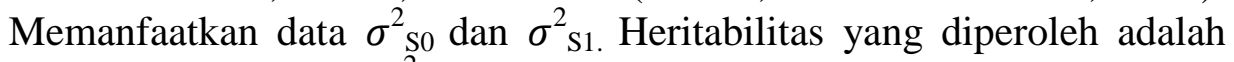
heritabiltas arti luas. $\left(\mathrm{h}^{2}{ }_{(\mathrm{BS})}\right)$.

$$
\mathrm{h}^{2}{ }_{(\mathrm{BS})}=\frac{\sigma_{\mathrm{S} 1}^{2}-\sigma_{\mathrm{S} 0}^{2}}{\sigma_{\mathrm{S} 1}^{2}} \times 100
$$

\section{HASIL DAN PEMBAHASAN}

\section{Heritabilitas dan Pengaruh Galur}

Menurut Jameela et al. (2014) Mudah tidaknya pewarisan karakter dapat diketahui dari nilai heritabilitas (h2) yang dapat diduga dengan membandingkan besar ragam genetik turunan dengan tetuanya. Heritabilitas Sanberasi M3 terhadap M2 bisa dilihat pada tabel 3.

\begin{tabular}{|c|c|c|c|c|c|c|c|}
\hline Galur & $\begin{array}{l}\text { Berat } \\
\text { Malai }\end{array}$ & $\begin{array}{c}\text { Panjang } \\
\text { Malai }\end{array}$ & $\begin{array}{c}\text { jumlah } \\
\text { malai }\end{array}$ & $\begin{array}{l}\text { jumlah } \\
\text { anakan }\end{array}$ & $\begin{array}{c}\text { Tinggi } \\
\text { Tanaman }\end{array}$ & Total & $\begin{array}{c}\text { Rata-Rata } \\
\text { Heritabilitas } \\
\text { M3 }(\%)\end{array}$ \\
\hline Sanbei 1 & $98,3 \mathrm{~T}$ & $4,8 \mathrm{R}$ & 40,9 CT & $-81,3 \mathrm{R}$ & $94,4 \mathrm{~T}$ & 157,1 & $31,4 \mathrm{CT}$ \\
\hline Sanbei 2 & $98,8 \mathrm{~T}$ & $66,8 \mathrm{~T}$ & $69 \mathrm{~T}$ & $-241,2 \mathrm{R}$ & $89,4 \mathrm{~T}$ & 82,8 & $16,6 \mathrm{R}$ \\
\hline Sanbei 3 & $97,7 \mathrm{~T}$ & $-42,8 \mathrm{R}$ & $84,7 \mathrm{~T}$ & $-56,8 \mathrm{R}$ & $73,2 \mathrm{~T}$ & 156,0 & $31,2 \mathrm{CT}$ \\
\hline S-V-1 & $87,6 \mathrm{~T}$ & $87,2 \mathrm{~T}$ & $71,1 \mathrm{~T}$ & $30,1 \mathrm{CT}$ & $95,7 \mathrm{~T}$ & 371,7 & $74,3 \mathrm{~T}$ \\
\hline S-50.a & $98,6 \mathrm{~T}$ & $16 \mathrm{R}$ & $89,8 \mathrm{~T}$ & $20,5 \mathrm{CT}$ & $54,1 \mathrm{~T}$ & 279,0 & $55,8 \mathrm{~T}$ \\
\hline S-1 & $98,4 \mathrm{~T}$ & $89,7 \mathrm{~T}$ & $83,1 \mathrm{~T}$ & $24,7 \mathrm{CT}$ & $52,2 \mathrm{~T}$ & 348,1 & $69,6 \mathrm{~T}$ \\
\hline
\end{tabular}

Tabel 3. Heritabilitas Sanberasi M3 terhadap induknya Sanberasi M2.

Analisis Variabilitas dan Heritibilitas Mutan Padi (Oryza Sativa L.) M3 Hasil Iradiasi Sinar Gamma Terhadap Sistem Pertanian Organik (Irsat Adanan Harahap, Efendi, Syafruddin)

Jurnal Ilmiah Mahasiswa Pertanian Unsyiah, Vol. 4, No. 1, Februari 2019: 139-148 


\begin{tabular}{|c|c|c|c|c|c|c|c|}
\hline S-53.a & $98 \mathrm{~T}$ & $-42,8 \mathrm{R}$ & $51,9 \mathrm{~T}$ & $-152,6 \mathrm{R}$ & $2,6 \mathrm{R}$ & 109,7 & $27,4 \mathrm{CT}$ \\
\hline S- 50 & $98,6 \mathrm{~T}$ & $-78,5 \mathrm{R}$ & $87,9 \mathrm{~T}$ & $-728,6 \mathrm{R}$ & $-533,3 \mathrm{R}$ & $-1153,9$ & $-230,8 \mathrm{R}$ \\
\hline S-10 & $98,3 \mathrm{~T}$ & $62,4 \mathrm{~T}$ & $91,9 \mathrm{~T}$ & $57,7 \mathrm{~T}$ & $-50,8 \mathrm{R}$ & 259,5 & $51,9 \mathrm{CT}$ \\
\hline S-6.b & $98,5 \mathrm{~T}$ & $24,5 \mathrm{CT}$ & $27,8 \mathrm{~T}$ & 3,3 R & $-187,9 \mathrm{R}$ & $-33,8$ & $-6,8 \mathrm{R}$ \\
\hline S-45 & $97,9 \mathrm{~T}$ & $-104 \mathrm{R}$ & $80,6 \mathrm{~T}$ & $-11,5 \mathrm{R}$ & $-150 \mathrm{R}$ & $-87,0$ & $-17,4 \mathrm{R}$ \\
\hline S-53.b & $97,4 \mathrm{~T}$ & $-19 \mathrm{R}$ & $82,2 \mathrm{~T}$ & $-623,0 \mathrm{R}$ & $2,1 \mathrm{R}$ & $-460,3$ & $-92,1 \mathrm{R}$ \\
\hline S-76 & $98 \mathrm{~T}$ & $55,4 \mathrm{~T}$ & $-62,5 \mathrm{R}$ & $-346,2 \mathrm{R}$ & $57,4 \mathrm{~T}$ & $-197,9$ & $-39,6 \mathrm{R}$ \\
\hline S-79 & $97,4 \mathrm{~T}$ & $47,1 \mathrm{CT}$ & $67,5 \mathrm{~T}$ & $-480 \mathrm{R}$ & $-66,7 \mathrm{R}$ & $-334,7$ & $-66,9 \mathrm{R}$ \\
\hline S-80 & $98 \mathrm{~T}$ & $-614,0 \mathrm{R}$ & $72,9 \mathrm{~T}$ & $-114,8 \mathrm{R}$ & $52,2 \mathrm{~T}$ & $-505,7$ & $-101,1 \mathrm{R}$ \\
\hline S-52 & $65,2 \mathrm{~T}$ & $87,2 \mathrm{~T}$ & $74 \mathrm{~T}$ & $-56,8 \mathrm{R}$ & $-5,6 \mathrm{R}$ & 164,0 & $32,8 \mathrm{CT}$ \\
\hline S-15 & $96,6 \mathrm{~T}$ & $70,3 \mathrm{~T}$ & $87,4 \mathrm{~T}$ & $14,7 \mathrm{R}$ & $61,5 \mathrm{~T}$ & 330,5 & $66,1 \mathrm{~T}$ \\
\hline S-66 & $97,7 \mathrm{~T}$ & $55,4 \mathrm{~T}$ & $43,5 \mathrm{~T}$ & $-56,8 \mathrm{R}$ & $37,5 \mathrm{CT}$ & 177,3 & $35,5 \mathrm{CT}$ \\
\hline S-5 & $97,6 \mathrm{~T}$ & $-104 \mathrm{R}$ & $69,8 \mathrm{~T}$ & $-480 \mathrm{R}$ & $64,1 \mathrm{~T}$ & $-352,5$ & $-70,5 \mathrm{R}$ \\
\hline S-21 & $98,9 \mathrm{~T}$ & $-104 \mathrm{R}$ & $85,9 \mathrm{~T}$ & $54,7 \mathrm{~T}$ & $-331,8 \mathrm{R}$ & $-196,3$ & $-39,3 \mathrm{R}$ \\
\hline S-36. b & $98,9 \mathrm{~T}$ & $81,5 \mathrm{~T}$ & $85,6 \mathrm{~T}$ & $-20,8 \mathrm{R}$ & 37,5 CT & 282,7 & $56,5 \mathrm{~T}$ \\
\hline S-67 & $97,8 \mathrm{~T}$ & $69,6 \mathrm{~T}$ & $93 \mathrm{~T}$ & $80,1 \mathrm{~T}$ & $95,8 \mathrm{~T}$ & 436,3 & $87,3 \mathrm{~T}$ \\
\hline S-22.b & $93,7 \mathrm{~T}$ & $83,8 \mathrm{~T}$ & $85,1 \mathrm{~T}$ & $33,3 \mathrm{CT}$ & $-427,8 \mathrm{R}$ & $-131,9$ & $-26,4 \mathrm{R}$ \\
\hline S-8 & $98,2 \mathrm{~T}$ & $49 \mathrm{CT}$ & $69,8 \mathrm{~T}$ & $-38,1 \mathrm{R}$ & $-50,8 \mathrm{R}$ & 128,1 & $25,6 \mathrm{CT}$ \\
\hline S-32 & $75,6 \mathrm{~T}$ & $42,9 \mathrm{CT}$ & $74 \mathrm{~T}$ & $37,6 \mathrm{CT}$ & $75,1 \mathrm{~T}$ & 305,2 & $61,0 \mathrm{~T}$ \\
\hline S-55 & $98,8 \mathrm{~T}$ & $35,1 \mathrm{CT}$ & $96 \mathrm{~T}$ & $82,0 \mathrm{~T}$ & $40,4 \mathrm{CT}$ & 352,3 & $70,5 \mathrm{~T}$ \\
\hline S-13 & $40,4 \mathrm{CT}$ & $49 \mathrm{CT}$ & $13,3 \mathrm{~T}$ & $-286,7 \mathrm{R}$ & $-322,2 \mathrm{R}$ & $-506,2$ & $-101,2 \mathrm{R}$ \\
\hline S-31 & $99 \mathrm{~T}$ & $49 \mathrm{CT}$ & $83,8 \mathrm{~T}$ & $14,7 \mathrm{R}$ & $-9,5 \mathrm{R}$ & 237,0 & $47,4 \mathrm{CT}$ \\
\hline S-46 & $86,2 \mathrm{~T}$ & $47,1 \mathrm{CT}$ & $85,1 \mathrm{~T}$ & $13,4 \mathrm{R}$ & $-617 \mathrm{R}$ & $-385,2$ & $-77,0 \mathrm{R}$ \\
\hline S-33.a & $91,2 \mathrm{~T}$ & $84,1 \mathrm{~T}$ & $90,4 \mathrm{~T}$ & $-222,2 \mathrm{R}$ & $68,5 \mathrm{~T}$ & 112,0 & $22,4 \mathrm{CT}$ \\
\hline S-72 & $96,5 \mathrm{~T}$ & $-376 \mathrm{R}$ & $59,4 \mathrm{~T}$ & $-241,2 \mathrm{R}$ & $-2,2 \mathrm{R}$ & $-463,5$ & $-92,7 \mathrm{R}$ \\
\hline S-44 & $94,4 \mathrm{~T}$ & $66 \mathrm{~T}$ & $88,5 \mathrm{~T}$ & $50,4 \mathrm{~T}$ & $72,7 \mathrm{~T}$ & 372,0 & $74,4 \mathrm{~T}$ \\
\hline S-47 & $98,5 \mathrm{~T}$ & $28,6 \mathrm{CT}$ & $94 \mathrm{~T}$ & $-38,1 \mathrm{R}$ & $-88,1 \mathrm{R}$ & 94,9 & $19,0 \mathrm{R}$ \\
\hline S-48 & $87,9 \mathrm{~T}$ & $80,2 \mathrm{~T}$ & $91,2 \mathrm{~T}$ & $-16 \mathrm{R}$ & $-26,7 \mathrm{R}$ & 216,6 & $43,3 \mathrm{CT}$ \\
\hline S-61 & $86,6 \mathrm{~T}$ & $77,3 \mathrm{~T}$ & $80,6 \mathrm{~T}$ & $24,7 \mathrm{CT}$ & $70,8 \mathrm{~T}$ & 340,0 & $68,0 \mathrm{~T}$ \\
\hline S-33 & $98 \mathrm{~T}$ & $89,2 \mathrm{~T}$ & $13,3 \mathrm{R}$ & $24,7 \mathrm{CT}$ & $-66,7 \mathrm{R}$ & 158,5 & $31,7 \mathrm{CT}$ \\
\hline S-51 & $72,2 \mathrm{~T}$ & $55,4 \mathrm{~T}$ & $13,3 \mathrm{R}$ & $-52,6 \mathrm{R}$ & $-66,7 \mathrm{R}$ & 21,6 & 4,3 R \\
\hline S-70 & $98 \mathrm{~T}$ & $69,6 \mathrm{~T}$ & $93,6 \mathrm{~T}$ & $36,9 \mathrm{CT}$ & $33,1 \mathrm{CT}$ & 331,2 & $66,2 \mathrm{~T}$ \\
\hline S-41 & $80 \mathrm{~T}$ & $47,1 \mathrm{CT}$ & $81,4 \mathrm{~T}$ & $84,6 \mathrm{~T}$ & $31,2 \mathrm{CT}$ & 324,3 & $64,9 \mathrm{~T}$ \\
\hline S-9.b & $98,3 \mathrm{~T}$ & $-78,5 \mathrm{R}$ & $53,6 \mathrm{~T}$ & $64,2 \mathrm{~T}$ & $88,1 \mathrm{~T}$ & 225,7 & $45,7 \mathrm{CT}$ \\
\hline
\end{tabular}

Keterangan : Heritabilitas kurang dari $20 \%=$ Rendah $(\mathrm{R}), 20-50 \%=$ Cukup Tinggi $(\mathrm{CT}),>50 \%=$ Tinggi $(\mathrm{T})$.

Dari tabel 3 Hasil rata-rata heritabilitas berat malai, panjang malai, jumlah malai, jumlah anakan dan tinggi tanaman, pada tabel 3 dapat disimpulkan beberapa galur M3 berheritabilitas tinggi terhadap galur M2. Galur heritabilitas paling tinggi dimiliki S-67 dengan heritabilitas 87,3\%, galur lain yang memiliki heritabilitas tinggi Sanberasi S-50.a, S-1, S-15, S-36.b, S-32, S-67, S-55, S-44, S61, S-70, S-V-1 dan S-41. Makin besar nilai heritabilitas makin besar kemajuan seleksi yang diraihnya dan makin cepat varietas unggul dilepas.

Hasil uji $\mathrm{F}$ menunjukkan bahwa galur tidak berpengaruh terhadap berat malai, berpengaruh nyata terhadap potensi hasil dan berpengaruh sangat nyata terhadap tinggi tanaman, jumlah anakan, jumlah malai dan panjang malai. Ratarata pertumbuhan padi bisa dilihat pada tabel 4 .

Tabel 4. Karakter Fisik Sanberasi M3 dan Sanbei .

\begin{tabular}{ccccccccc}
\hline Galur & $\begin{array}{c}\text { Jumlah } \\
\text { Malai } \\
(\text { Helai) }\end{array}$ & $\begin{array}{c}\text { Panjang } \\
\text { Malai } \\
(\mathbf{C m})\end{array}$ & $\begin{array}{c}\text { Berat } \\
\text { Malai } \\
(\text { gram })\end{array}$ & $\begin{array}{c}\text { Tinggi } \\
\text { Tanaman } \\
(\mathbf{c m})\end{array}$ & $\begin{array}{c}\text { Jumlah } \\
\text { Anakan } \\
(\text { batang) }\end{array}$ & $\begin{array}{c}\text { Umur } \\
\text { berbunga } \\
(\text { Hari })\end{array}$ & $\begin{array}{c}\text { Umur } \\
\text { Panen } \\
(\text { Hari })\end{array}$ & $\begin{array}{c}\text { Potensi } \\
\text { Hasil } \\
(\text { ton/ha) }\end{array}$ \\
\hline
\end{tabular}

Analisis Variabilitas dan Heritibilitas Mutan Padi (Oryza Sativa L.) M3 Hasil Iradiasi Sinar Gamma Terhadap Sistem Pertanian Organik (Irsat Adanan Harahap, Efendi, Syafruddin)

Jurnal Ilmiah Mahasiswa Pertanian Unsyiah, Vol. 4, No. 1, Februari 2019: 139-148 


\begin{tabular}{|c|c|c|c|c|c|c|c|c|}
\hline Sanbei 1 & $10,2 \mathrm{Ak}$ & 28 b P & $34,7 \mathrm{~S}$ & $141,8 \mathrm{e} \mathrm{T}$ & 13,2 a $\mathrm{S}$ & $87,8 \mathrm{w} \mathrm{L}$ & $113,4 \mathrm{~mL}$ & $7,8 \mathrm{~b} \mathrm{H}$ \\
\hline Sanbei 2 & 10,8 a $\mathrm{K}$ & 29,7 с P & $37,6 \mathrm{~S}$ & 141,6 e T & 12,8 a S & 87,8 w L & $113,2 \mathrm{~mL}$ & $9,1 \mathrm{~b} \mathrm{H}$ \\
\hline Sanbei 3 & 9 a K & 29,5 c P & $29,4 \mathrm{~S}$ & 141,7 e $\mathrm{T}$ & 12,8 a S & 79,6 o L & $110,6 \mathrm{j} \mathrm{M}$ & 7,0 a $\mathrm{R}$ \\
\hline S-V-1 & 10 a K & 26,4 a $S$ & $27,5 \mathrm{~S}$ & 127 c T & 12,2 a $\mathrm{S}$ & 67 c C & $106 \mathrm{f} \mathrm{L}$ & 6,8 a $R$ \\
\hline S-50.a & 12,2 a K & 27,6 a $\mathrm{P}$ & $33,5 \mathrm{~S}$ & 112,2 a S & 14,6 a $S$ & 69 e $C$ & 103 c L & 8,3 b H \\
\hline S-1 & $12,8 \mathrm{~b} \mathrm{~S}$ & 27,3 a $\mathrm{P}$ & $40,1 \mathrm{~S}$ & 117 b S & 14,4 a S & 69 e $C$ & 103 c L & $10,2 \mathrm{bH}$ \\
\hline S-53.a & 9,8 a K & 28,5 b P & $34,2 \mathrm{~S}$ & 118,5 b S & 12,6 a $S$ & $66 \mathrm{~b} \mathrm{C}$ & 101 a M & 8,1 b H \\
\hline S- 50 & $13,3 \mathrm{~b} \mathrm{~S}$ & 28,7 b P & $39,7 \mathrm{~S}$ & $119 \mathrm{~b} \mathrm{~S}$ & $16,4 \mathrm{~b} \mathrm{~S}$ & 69 e C & 103 c L & $10,0 \mathrm{bH}$ \\
\hline S-10 & 11 a K & 27,7 b P & $32,0 \mathrm{~S}$ & 112,6 a S & 14,8 a $S$ & $70,4 \mathrm{f} \mathrm{M}$ & 105 e L & 8,0 b H \\
\hline S-6.b & 13,4 b S & 28,4 b P & $34,9 \mathrm{~S}$ & 112,4 a S & 15,6 b S & $70,4 \mathrm{f} \mathrm{M}$ & 105 e L & $10,7 \mathrm{bH}$ \\
\hline S-45 & 9,8 a K & 26,4 a S & $28,2 \mathrm{~S}$ & 116,6 a $S$ & 15,6 b S & 69 e $\mathrm{C}$ & $104 \mathrm{~d} \mathrm{~L}$ & 6,8 a $\mathrm{R}$ \\
\hline S-53.b & 10,4 a K & 27,6 a $\mathrm{P}$ & $33,5 \mathrm{~S}$ & 116,2 a $S$ & 14,8 a $S$ & $70 \mathrm{f} \mathrm{M}$ & 105 e L & $8,3 \mathrm{~b} \mathrm{H}$ \\
\hline S-76 & 12,4 a K & 29,4 c P & $34,7 \mathrm{~S}$ & 110,6 a S & 14,6 a $S$ & $70,4 \mathrm{f} \mathrm{M}$ & 105 e L & 8,4 b H \\
\hline S-79 & 10 a K & 27,4 a $\mathrm{P}$ & $26,0 \mathrm{~S}$ & 117,2 b S & 13 a S & $71 \mathrm{~g} \mathrm{C}$ & 106 f L & 5,9 a $\mathrm{R}$ \\
\hline S-80 & 9,4 a K & 27,9 b P & $29,4 \mathrm{~S}$ & $117 \mathrm{~b} \mathrm{~S}$ & 13,2 a $S$ & 69 e C & $104 \mathrm{~d} \mathrm{~L}$ & 7,2 a $\mathrm{R}$ \\
\hline$S-52$ & 11 a K & 27,9 b P & $34,6 \mathrm{~S}$ & $120 \mathrm{~b} \mathrm{~S}$ & 13,8 a S & $70 \mathrm{f} \mathrm{M}$ & 105 e L & 8,8 b R \\
\hline S-15 & 9,4 a K & 27,7 b P & $25,0 \mathrm{R}$ & 110,8 a S & 13,2 a $\mathrm{S}$ & 73 i L & $107 \mathrm{~g} \mathrm{~L}$ & 6,4 a $\mathrm{R}$ \\
\hline S-66 & 10,4 a K & 26,9 a $P$ & $28,7 \mathrm{~S}$ & 113,3 a $S$ & 13 a S & $67 \mathrm{c} \mathrm{C}$ & 102 b L & 7,1 a $\mathrm{R}$ \\
\hline S-5 & 11,4 a K & 28,4 b P & $32,4 \mathrm{~S}$ & 118,06 b S & 14,6 a $S$ & $70 \mathrm{f} \mathrm{M}$ & $106,4 \mathrm{f} \mathrm{L}$ & 7,9 b H \\
\hline S-21 & 12,2 a K & 28,1 b P & $33,8 \mathrm{~S}$ & 120,2 b S & 14,8 a S & $71 \mathrm{~g} \mathrm{~L}$ & $106 \mathrm{f} \mathrm{L}$ & 8,2 b H \\
\hline S-36. b & $15 \mathrm{~b} \mathrm{~S}$ & 28,9 b P & $39,0 \mathrm{~S}$ & 119,7 b S & 18,6 c B & 69 e C & $104 \mathrm{~d} \mathrm{~L}$ & 9,5 b H \\
\hline S-67 & 10,2 a K & 28,1 b P & $26,5 \mathrm{~S}$ & 115,6 a S & 12,8 a $\mathrm{S}$ & $67 \mathrm{c} \mathrm{C}$ & 102 b L & 4,6 a $\mathrm{R}$ \\
\hline S-22.b & 13,2 b S & 28,3 b P & $37,1 \mathrm{~S}$ & 119,9 b S & 13,2 a $S$ & 69 e C & $105 \mathrm{~d} \mathrm{~L}$ & $8,3 \mathrm{~b} \mathrm{H}$ \\
\hline S-8 & 12,4 a K & 26,8 a $\mathrm{P}$ & $34,8 \mathrm{~S}$ & 119,6 b S & 14,2 a S & $72 \mathrm{~h} \mathrm{~L}$ & $107 \mathrm{~g} \mathrm{~L}$ & $8,3 \mathrm{~b} \mathrm{H}$ \\
\hline S-32 & $16 \mathrm{~b} \mathrm{~S}$ & 27 a P & $40,8 \mathrm{~S}$ & 113,8 a S & $18,8 \mathrm{c} \mathrm{B}$ & 73 i L & $107,2 \mathrm{~g} \mathrm{~L}$ & $9,9 \mathrm{~b} \mathrm{H}$ \\
\hline S-55 & $11,2 \mathrm{aK}$ & 27,9 b P & $30,1 \mathrm{~S}$ & 113,3 a $S$ & 13,6 a $S$ & 65 a C & $101,2 \mathrm{aM}$ & 7,1 a H \\
\hline S-13 & 10 a K & 27,8 b P & $31,5 \mathrm{~S}$ & 119,5 b S & 13,6 a $S$ & $70 \mathrm{f} \mathrm{M}$ & $106,2 \mathrm{f} \mathrm{C}$ & 7,7 b H \\
\hline S-31 & $15 \mathrm{~b} \mathrm{~S}$ & 27,3 a $P$ & $42,7 \mathrm{~S}$ & 119,4 b S & 17,8 b S & 69 e C & $104,2 \mathrm{~d} \mathrm{C}$ & 9,9 b H \\
\hline S-46 & $10,2 \mathrm{aK}$ & 28,4 b P & $27,2 \mathrm{~S}$ & 117,8 b S & 13,4 a $S$ & 65 a C & 101 a M & 6,2 a $R$ \\
\hline S-33.a & $13 \mathrm{~b} \mathrm{~S}$ & 26,5 a S & $34,8 \mathrm{~S}$ & 117,4 b S & 14,8 a $S$ & 67,4 c C & 102 b L & 8,4 b H \\
\hline S-72 & $10,8 \mathrm{aK}$ & 27,3 a $P$ & $28,6 \mathrm{~S}$ & 118,4 b S & 13,8 a S & $66,4 \mathrm{~b} \mathrm{C}$ & 101 a M & 6,9 a $\mathrm{R}$ \\
\hline S-44 & $13,6 \mathrm{bS}$ & $28,1 \mathrm{~b} \mathrm{P}$ & $44,0 \mathrm{~S}$ & 119,9 b S & 16,4 b S & 69 e $C$ & 105 e $\mathrm{L}$ & $10,8 \mathrm{cH}$ \\
\hline S-47 & 12 a K & 28 b P & $37,0 \mathrm{~S}$ & 118,1 b S & 15,6 b S & $70 \mathrm{f} \mathrm{M}$ & $106 \mathrm{f} \mathrm{L}$ & 7,2 a $\mathrm{R}$ \\
\hline S-48 & $11,4 \mathrm{aK}$ & 27,4 a $\mathrm{P}$ & $32,9 \mathrm{~S}$ & 116 a $S$ & $15,4 \mathrm{~b} \mathrm{~S}$ & $70 \mathrm{f} \mathrm{M}$ & $106 \mathrm{f} \mathrm{L}$ & $8,5 \mathrm{~b} \mathrm{H}$ \\
\hline S-61 & 9,2 a $\mathrm{K}$ & 27,8 b P & $25,9 \mathrm{R}$ & 110 a S & 13,2 a $S$ & 66 b C & 102 b L & 6,9 a $\mathrm{H}$ \\
\hline S-33 & 11 a K & 28,6 b P & $32,7 \mathrm{~S}$ & 116,2 a $S$ & 14 a S & 69 e C & 105 e L & $8,0 \mathrm{~b} \mathrm{H}$ \\
\hline S-51 & 11 a K & 29,4 c P & $30,3 \mathrm{~S}$ & 116,2 a $S$ & 14,2 a S & $74 \mathrm{j} \mathrm{L}$ & $108 \mathrm{~h} \mathrm{~L}$ & 7,8 b H \\
\hline S-70 & $14,6 \mathrm{bS}$ & 28,6 b P & $34,8 \mathrm{~S}$ & 112,7 a S & 18,6 c B & $66 \mathrm{~b} \mathrm{C}$ & 102 b L & 8,2 b H \\
\hline S-41 & $13 \mathrm{~b} \mathrm{~S}$ & 26,4 a $S$ & $33,5 \mathrm{~S}$ & 117,4 b S & 17,2 a $S$ & 73 i L & $107 \mathrm{~g} \mathrm{~L}$ & 8,8 b H \\
\hline S-9.b & $11,4 \mathrm{aK}$ & 28,3 b P & $35,0 \mathrm{~S}$ & $134,8 \mathrm{~cd} \mathrm{~S}$ & $15,6 \mathrm{~b} \mathrm{~S}$ & $70 \mathrm{f} \mathrm{M}$ & $105,2 \mathrm{e} \mathrm{L}$ & 8,7 b H \\
\hline BNT. 0,05 & 3,7 & 2,6 & & $\mathbf{7 , 0}$ & $\mathbf{3 , 0}$ & 0,4 & $\mathbf{0 , 3}$ & $\mathbf{3 , 8}$ \\
\hline M2 & 13,4 & 26,8 & 51,6 & 117 & 15,4 & 70,8 & 100,8 & 9,0 \\
\hline
\end{tabular}

Keterangan : Angka yang diikuti oleh Huruf Kecil yang sama pada kolom yang sama tidak berbeda nyata ( Uji BNT $\alpha$ 0,05). Keterangan Karakter Sanberasi M3 dengan lambang Huruf Besar : Tinggi (T), Sedang (S), Sedikit (K), Panjang (P), Banyak (B), Berat (H), Ringan (R), Sama Hari dengan M2=0,9 - $-0,9(\mathrm{M})$, Lebih Cepat dari M2 $=<-1(\mathrm{C})$, Lebih Lama dari M2 $=>1$ (L).

\section{Pengaruh Galur terhadap Heritabilitas Tinggi Tanaman}

Pada tabel dapat dilihat M3 yang paling rendah heritabilitasnya S-46, dengan $-617,0 \%$, dengan karakter batang berukuran sedang $117,8 \mathrm{~cm}$. Galur yang masuk dalam heritabilitas rendah S-53.a, S-10, S-6.b, S-45, S-53.b, S-79, S-52, S21, S-8, S-13, S-31, S-72, S-47, S-48,S-50, S-22.b, S-33, dan S-51. Rendahnya nilai heritabilitas menunjukkan lingkungan lebih berpengaruh dibandingkan gen tanaman. Rendahnya keragaman mengakibatkan rendah nilai heritabilitas. Semakin rendah nilai heritabilitas makin kecil kemajuan seleksi diperoleh dan semakin lama varietas unggul baru diperoleh.

Heritabilitas Cukup Tinggi diantaranya S-41 dengan heritabilitas 31,2\% dengan karakter batang sedang $117,4 \mathrm{~cm}$, sanbei lain berheritabilitas cukup tinggi S-70 , S-66 dan S-36.b. Heritabilitas paling Tinggi dimiliki S-67 dengan heritabilitas 95,81\% dengan karakter batang berukuran sedang 115,6 cm . Galur

Analisis Variabilitas dan Heritibilitas Mutan Padi (Oryza Sativa L.) M3 Hasil Iradiasi Sinar Gamma Terhadap Sistem Pertanian Organik (Irsat Adanan Harahap, Efendi, Syafruddin)

Jurnal Ilmiah Mahasiswa Pertanian Unsyiah, Vol. 4, No. 1, Februari 2019: 139-148 
yang memiliki heritabilitas tinggi S-50.a, S-1, S-76, S-80, S-15, S-5, S- S-32, S33, S-V-1, S-44, S-61, S-9.b, Sanbei 1, Sanbei 3 dan Sanbei 2. Makin besar nilai heritabilitas makin besar kemajuan seleksi yang diraihnya dan makin cepat varietas unggul dilepas.

\section{Pengaruh Galur terhadap Heritabilitas Jumlah Anakan}

Pada tabel 3 dapat dilihat heritabilitas paling rendah adalah S-50 dengan heritabilitas $-738,57 \%$, dengan jumlah anakan sedang 16,4 anakan. Galur M3 yang berheritabilitas rendah antara lain Sanbei 1, Sanbei 2, Sanbei 3, S-53.a, S50, S-6.b, S-45, S-53.b, S-76, S-79, S-80, S-52, S-15, S-66, S-5, S-48, S-51, S47, S-72, S-33, S-46, S-31, S-13, S-8, dan S-36.b. Heritabilitas rendah karena keragaman padi mutan lebih rendah dari tetuanya. Seleksi pada generasi awal dilakukan bila nilai heritabilitas tinggi, sebaliknya jika rendah maka seleksi pada generasi lanjut akan berhasil karena peluang terjadi peningkatan keragaman dalam populasi (Falconer, 1989).

Galur M3 yang berheritabiltas cukup tinggi terdiri dari S-70, S-33, S-61, S-32, S-22.b, S-V1, S-50.a, dan S-1. M3 yang memiliki heritabilitas tinggi seperti S-21, S-9.b, S-41, S-44, S-55, S-67 dan S-50. M3 paling tinggi heritabilitasnya adalah S-41 dengan heritabilitas 84,61\%, dengan jumlah anakan sedang 17,2 anakan. Dahlan dan Slamet (1992) menyatakan bahwa heritabilitas menentukan kemajuan seleksi, makin besar nilai heritabilitas makin besar kemajuan seleksi yang diraihnya dan makin cepat varietas unggul dilepas.

\section{Pengaruh Galur terhadap Heritabilitas Jumlah Malai}

Dari tabel 3 dapat dilihat heritabilitas paling rendah adalah S-76 heritabilitas $-62,5 \%$ dengan karakter jumlah malai sedikit 12,4 malai, M3 berheritabilitas rendah lainnya S-13, S-51 dan S-33. Dilapangan heritabilitas dapat saja diperoleh nilai negatif yang berarti nilai ragamnya kecil.

Galur M3 yang memiliki heritabilitas cukup tinggi diantaranya S-66 heritabilitas 43,5\%, S-66.b, 22,7 \% dan Sanbei 1 heritabilitas 40,9\%. Sabu et al. (2009) melaporkan bahwa karakter hasil gabah, jumlah malai per rumpun, dan bobot 1000 butir dengan nilai keragaman genetik yang relatif sempit disebabkan oleh dekatnya kekerabatan sebagian besar genotip yang diuji.

M3 berheritabilitas tinggi seperti S-21, S-5, S-15,S-52,S-80, S-79, S-53.b, S-45, S-10,S-50, S-53.a, S-1, S-50.a, S-V-1, S-9.b, S-41,S-70, S-61, S-48,S-47,S44,S-72, S-33,S-46,S-31, S-55, S-32, S-8,S-22.b, S-67,S-36.b, Sanbei 3, Sanbei 2 dan Sanbei 1. Galur M3 yang memiliki nilai heritabilitas paling tinggi adalah S-55 heritabilitas 96,0 \%, dengan karakter jumlah malai sedikit 11,2 malai. Nilai heritabilitas yang tinggi berarti faktor genetik memberikan kontribusi penting dalam proses seleksi berikutnya. Nilai heritabilitas menunjukkan bagaimana proporsi suatu gen dapat diturunkan pada generasi berikutnya berdasarkan observasi sifat fenotipe yang diamati. (Sabu et al., 2009).

\section{Pengaruh Galur terhadap Heritabilitas Panjang Malai}

Dari tabel heritabilitas panjang malai yang paling rendah adalah S-80 heritabilitas $-614,0 \%$, dengan karakter malai berukuran panjang $27,9 \mathrm{~cm}$. Galur

Analisis Variabilitas dan Heritibilitas Mutan Padi (Oryza Sativa L.) M3 Hasil Iradiasi Sinar Gamma Terhadap Sistem Pertanian Organik (Irsat Adanan Harahap, Efendi, Syafruddin)

Jurnal Ilmiah Mahasiswa Pertanian Unsyiah, Vol. 4, No. 1, Februari 2019: 139-148 
M3 berheritabilitas rendah antara lain S-21, S-5, S-80, S-53.b, S-45, S-9, S-72, S50, S-53.a, S-50.a, Sanbei 1 dan Sanbei 3. Heritibilitas panjang malai cukup tinggi dimiliki S-41, S-47, S-79, S-6.b, S-46, S-31, S-13, S-55, S-32 dan S-8. Galur berheritibilitas tinggi dimiliki S-70, S-51, S-33, S-61, S-48, S-44, S-33, S66, S-15, S-52, S-76, S-10, S-1, S-V-1, S-36.b, S-67, S-22.b. dan Sanbei 2.

Galur dengan heritibilitas paling tinggi S-1 dengan heritabilitas 89,7\%, dengan karakter malai berukuran panjang $27,3 \mathrm{~cm}$. Nilai heritabilitas tinggi menunjukkan keragaman yang muncul untuk karakter-karakter tersebut lebih dipengaruhi oleh faktor genetik dibandingkan dengan faktor lingkungan.

\section{Pengaruh Galur terhadap Heritabilitas Berat Malai}

Semua Sanberasi M3 memiliki heritabilitas tinggi (T) terhadap berat malai, berheritabilitas tinggi terkecil dimiliki S-13 dengan nilai heritabilitas $40,44 \%$, dengan karakter malai berberat sedang 31,5 gram . M3 yang memiliki nilai heritabilitas paling tinggi nilainya terhadap berat malai adalah S-31 dengan heritabilitas 98,97\% dengan karakter malai berberat sedang 42,7 gram, . Galur M3 mampu memiliki heritabilitas tinggi dibanding di banding tetuanya Sanbei, ini merupakan kemajuan secara genetik.

Nilai heritabilitas yang tinggi menunjukkan faktor genetik lebih berperan dalam mengendalikan suatu sifat dibandingkan dengan faktor lingkungan (Barmawi et al., 2013). Heritabilitas (daya waris) menentukan kemajuan seleksi, makin besar nilai heritabilitas makin besar pula kemajuan seleksi, dan sebaliknya. Karakter seleksi harus memiliki keragaman dan heritabilitas yang tinggi, agar diperoleh target kemajuan seleksi (Lubis et al., 2014).

\section{Heritabilitas Sanberasi M3 terhadap M2.}

Dari Hasil rata-rata heritabilitas berat malai, panjang malai, jumlah malai, jumlah anakan dan tinggi tanaman, pada tabel 3 dapat disimpulkan beberapa galur M3 berheritabilitas tinggi terhadap galur M2. Galur heritabilitas paling tinggi dimiliki S-67 dengan heritabilitas 87,3\%, galur lain yang memiliki heritabilitas tinggi Sanberasi S-50.a, S-1, S-15, S-36.b, S-32, S-67, S-55, S-44, S-61, S-70, SV-1 dan S-41. Pada sifat yang memiliki heritabilitas tinggi, seleksi akan berlangsung efektif karena pengaruh lingkungan sangat kecil sehingga faktor genetik lebih besar dalam penampilan fenotipenya (Pinaria, 1995). Nilai heritabilitas yang tinggi untuk karakter tersebut menunjukkan bahwa pengaruh faktor genetik lebih besar dibandingkan faktor lingkungan. Makin besar nilai heritabilitas makin besar kemajuan seleksi yang diraihnya dan makin cepat varietas unggul dilepas. Seleksi pada generasi awal dilakukan bila nilai heritabilitas tinggi, sebaliknya jika rendah maka seleksi pada generasi lanjut akan berhasil karena peluang terjadi peningkatan keragaman dalam populasi (Falconer, 1970)

Heritabilitas Cukup Tinggi diantaranya Sanbei 1 dengan heritabilitas 31,4 \%. Galur lainnya berheritabiltas cukup tinggi Sanbei 3, S-53.a, S-10, S-66, S-52, S-8, S-31, S-33.a, S-48, S-33 dan S-99.b. Heritabilitas dalam arti sempit banyak mendapatkan perhatian karena pengaruh aditif dari tiap alelnya diwariskan dari tetua kepada keturunannya. Dalam pemuliaan tanaman, seleksi karakter-karakter

Analisis Variabilitas dan Heritibilitas Mutan Padi (Oryza Sativa L.) M3 Hasil Iradiasi Sinar Gamma Terhadap Sistem Pertanian Organik (Irsat Adanan Harahap, Efendi, Syafruddin)

Jurnal Ilmiah Mahasiswa Pertanian Unsyiah, Vol. 4, No. 1, Februari 2019: 139-148 
yang dikendalikan oleh gen adiktif diharapkan mendapatkan kemajuan seleksi yang besar dan cepat.

Galur S-50, dengan heritabilitas $-230,8 \%$ merupakan galur paling rendah heritabiltasnya dibanding galur lainnya. Galur yang masuk dalam berheritabilas rendah Sanbei 2, Sanbei 3, S-72, S-13, S-80, S-53.a, S-6.b, S-45, S-76, S-79, S-5, S-21, S-22.b, S-46, S-47, dan S-51. Heritabilitas rendah karena keragaman padi mutan lebih rendah dari tetuanya. Bila tingkat keragaman genetik sempit maka hal ini menunjukkan bahwa individu dalam populasi tersebut relatif seragam. Semakin rendah nilai heritabilitas arti sempit makin kecil kemajuan seleksi diperoleh dan semakin lama varietas unggul baru diperoleh. Perbedaan tingkat radiosensitivitas suatu eksplan terhadap iradiasi dipengaruhi antara lain oleh bentuk fisik dan bentuk morfologi eksplan yang dapat mempengaruhi ketahanan fisik sel saat menerima iradiasi sinar gamma (Roux, 2004), selain itu kondisi fisiologis, genetik, dan faktor lingkungan seperti kadar air eksplan, penyimpanan pasca iradiasi dan suhu saat inkubasi (Soeranto, 2003).

\section{KESIMPULAN DAN SARAN}

\section{Kesimpulan}

Berdasarkan hasil penelitian pengaruh lintasan traktor roda empat dan pemberian pupuk organik terhadap pertumbuhan dan produksi kacang buncis, dapat diambil beberapa kesimpulan sebagai berikut:

1. Galur yang memiliki rata-rata heritabilitas tinggi, yaitu Sanberasi S-V-1, S50.a, S-1, S-10, S-15, S-36.b, S-67, S-32, S-55, S-44, S-61, S-70 dan S-41.

2. Galur yang memiliki rata-rata heritabilitas cukup tinggi, yaitu Sanbei 1, Sanbei 3, S-53.a, S-10, S-52, S-66, S-8, S-31, S-33.a, S-48, S-33, dan S-9.b.

3. Galur yang memiliki rata-rata heritabilitas rendah, yaitu Sanbei 2, S-50, S-6.b, S-45,S-53.b, S-76, S-79, S-80, S-5, S-21, S-22.b, S-13, S-46, S-72, S-47, dan S-51.

\section{DAFTAR PUSTAKA}

Alamsyah, W. 2016. Uji Viabilitas dan Vigor Benih serta Performasi pada Fase Vegetatif Tanaman Padi (Oryza sativa L.) Lokal Aceh Hasil Iradiasi Sinar Gamma yang Dibudidayakan Secara Organik. Prodi Agroteknologi. Fakultas Pertanian. Universitas Syiah Kuala. Banda Aceh.

Barmawi, M., N. Sa'diyah dan E. Yantama. 2013. Kemajuan Genetik dan Heritabilitas Karakter Agronomi Kedelai (Glycine max [L.] Merrill) Generasi F2 Persilangan Wilis dan Mlg2521. Prosiding Semirata FMIPA Universitas Lampung

Dahlan, M.M. dan S. Slamet. 1992. Pemuliaan Tanaman Jagung.p. 17-38. Dalam:

A. Kasno, M. Dahlan, dan Hasnam. Prosiding Simposium Pemuliaan Tanaman 1. PPTI Jawa Timur. p. 439.

Falconer, D.S. 1970. Introduction To Quantitative Genetics. The Ronald Company Press. New York. 224 hal.

Analisis Variabilitas dan Heritibilitas Mutan Padi (Oryza Sativa L.) M3 Hasil Iradiasi Sinar Gamma Terhadap Sistem Pertanian Organik (Irsat Adanan Harahap, Efendi, Syafruddin)

Jurnal Ilmiah Mahasiswa Pertanian Unsyiah, Vol. 4, No. 1, Februari 2019: 139-148 
Google Earth. 2016. http://www.googleearth.co.id. Fakultas Pertanian Unsyiah. (Diakses pada tanggal 1 Maret 2016).

Jameela, H., A. N. Sugiharto, dan A. Soegianto. 2014. Keragaman genetik dan heritabilitas komponen hasil pada populasi F2 buncis (Phaseolus vulgaris L.) hasil persilangan varietas introduksi dengan varietas lokal. J. Produksi Tanaman 2(4):324-32.

Kalton, R. R., A. G. Smith, and R. C. Leffel. 1952. Parent-inbread Progeny Relationship of Selected Orchard Grass Clones. Agron. J. 44:481-486.

Lubis, K., S.H. Sutjahjo, M. Syukur, dan Trikoesoemaningtyas. 2014. Pendugaan Parameter genetik dan seleksi karakter morfofisiologi galur jagung introduksi di lingkungan tanah masam. J. Penelitian Pertanian Tanaman Pangan 33(2): 122- 128

Pinaria, A. A. Baihaki, R. Setiamihardja, dan A. A. Darajat. 1995. Variabilitas Genetik dan Heritabilitas Karakter-Karakter Biomasa 53 Genotipe Kedelai. Zuriat 6(2): 88-92.

Putra, G. A., Efendi, dan Syamsuddin. 2016. Pengujian Ketahanan Kekeringan Padi Mutan Hasil Irradiasi Sinar Gamma Pada Media In Vitro. Unsyiah. Banda Aceh.

Roux, NS. 2004. Mutation Induction in Musa-a review, in Jain, SM \& Swennen, R (eds.), Banana molecular biology and induced mutations', Enfield. Sci. Pub. Inc., pp. 21-9.

Sabu, KK, MZ Abdullah, LS Lim dan Wickneswari, 2009. Analisis heritabilitas dan varian genetik penting secara agronomi ciri-ciri dalam persilangan oryza sativa x O. Rufipogon. Agronomi Res., 7: 73-76.

Soeranto, H. 2003.Peran Iptek nuklir dalam pemuliaan tanaman untuk mendukung Industri pertanian. Puslitbang Teknologi Isotop dan Radiasi. Jakarta:Badan Tenaga Nuklir Nasional.

Syukur, M., S. Sujiprihati, R . Yunianti, dan M. A. Rifai. 2012. Teknik Pemuliaan Tanaman. Penebar Swadaya. Jakarta.

Analisis Variabilitas dan Heritibilitas Mutan Padi (Oryza Sativa L.) M3 Hasil Iradiasi Sinar Gamma Terhadap Sistem Pertanian Organik (Irsat Adanan Harahap, Efendi, Syafruddin)

Jurnal Ilmiah Mahasiswa Pertanian Unsyiah, Vol. 4, No. 1, Februari 2019: 139-148 